\title{
Network centrality and social movement media coverage: A two-mode network analytic approach ${ }^{\text {is }}$
}

\author{
Todd E. Malinick ${ }^{\text {a }}$, D.B. Tindall ${ }^{\mathrm{b}, *}$, Mario Diani ${ }^{\mathrm{c}}$ \\ a Energy Market Innovations, Inc., United States \\ ${ }^{\mathrm{b}}$ Department of Sociology, and Department of Forest Resources Management, University of British Columbia, Canada \\ c ICREA-Universitat Pompeu Fabra, Barcelona, Spain
}

\section{A R T I C L E I N F O}

\section{Keywords:}

Social movements

Networks

Two-mode

Media

Framing

Environmental activism

\begin{abstract}
A B S T R A C T
This article examines the relationship between structural location (namely, degree centrality) and news media coverage. Our central hypothesis is that the network centrality of social movement actors is positively associated with the prevalence of actors being cited in the print news media. This paper uses two-mode data from a communication network of environmentalists in British Columbia, and examines the relationship between their structural location and the frequency by which they are cited in newsprint media with regard to particular frames (about forest conservation, environmental protest, and related issues). We asked a sample of social movement participants about their ties to a target list of relatively high profile actors (environmental activists). We turned the resulting network matrix into a bipartite graph that examined the relationships amongst the target actors vis a vis the respondents. Next we calculated point in-degree for the target actors. For the target actors we also have data from a representative sample of 957 print news articles about forestry and conservation of old growth forests in British Columbia. We compare the effects of network centrality of the target actor versus several attributes of the target actors (gender, level of radicalism, leadership status) on the amount of media coverage that each of the target actors receives. We find that network centrality is associated with media coverage controlling for actor attributes. We discuss theoretical implications of this research. Finally, we also discuss the methodological pros and cons of using a "target name roster" to construct two-mode data on social movement activists.
\end{abstract}

(C) 2011 Elsevier B.V. All rights reserved.

\section{Introduction}

The relationship between social movements and media has long been viewed as a complex and dynamic interaction. Social movements rely on news coverage to draw critically needed attention to their cause; the news industry values the attention that vociferous and contentious movement activities and events can attract (Gamson and Wolfsfeld, 1993:115). An array of different factors can affect what movement messages actually make it into the

\footnotetext{
This research was supported by a Research Development Initiatives Grant from the Social Sciences and Humanities Research Council of Canada (\# 820-2005-1033). An earlier version of this paper was presented at the Sunbelt Social Network Conference in Corfu, Greece, in May 2007. We would like to thank the following people for their contributions to this research at various stages: Jeff Cormier, Rima Wilkes, Sean Lauer, Bob Brulle, Bonnie Erickson, Barry Wellman, Aaron Doyle, Chantelle Marlor, Kamaljit Kaur Inman-Bates, John Nunan, and Mark Stoddart. We would also like to thank the anonymous reviewers of this article.

* Corresponding author at: Department of Sociology, University of British Columbia, 6303 N.W. Marine Drive, Vancouver, BC, Canada V6T 1 Z1. Tel.: +1 604822 2363; fax: +1 6048226161 .

E-mail address: tindall@mail.ubc.ca (D.B. Tindall).
}

news. These include structural (social, political, and economic) opportunities and constraints; struggles over meaning and message construction; and the personal values, ideologies, and news reporting practices of individual journalists (see e.g. Gamson and Modigliani, 1989; Gamson and Wolfsfeld, 1993).

In this paper we contribute to this discussion from a distinctive angle, asking whether media coverage of social movements is affected by the properties of the activists mobilizing within them. We conceptualize such properties under two broad categories. One the one hand, we look at some individual attributes that are often treated in the literature as predictors of differential access to the media. These include the assumption of formal leadership roles within specific organizations, levels of radicalism, and gender. On the other hand, we introduce an explicit relational dimension to analysis, by exploring the correlation between media coverage and the position that activists occupy within movement networks. Building on earlier contributions (Diani, 2003), we ask in particular whether media attention to specific activists is positively related to their centrality in movement networks.

Our empirical evidence comes from multiple datasets related to the conflict over preserving the old growth forests of coastal British Columbia in the highly contentious 1990s. We evaluate how 
environmental activists' individual attributes and their centrality in the environmental movement's communication network relate to the frequency with which activists are cited in print-news media. In order to build the movement network we use a 2-mode strategy, namely, we include in the environmental network all the environmental activists mentioned on a name roster by a smaller number of informants.

\section{Literature}

\subsection{Media and social movements' impact}

In order to be influential, whether on the policy process, on cultural models, or on both, social movements need to attract the support of the general public, mobilize adherents, and exert pressure on their opponents (Snow and Benford, 1988; Gamson and Modigliani, 1989; Cohn et al., 2003). Interaction with the media is one of the main ways to accomplish these tasks (Gamson and Wolfsfeld, 1993; Oliver and Meyer, 2003; Ryan, 1991). News media significantly influence citizens' interest in, opinions of, and, maybe most importantly, exposure to, various contentious issues, including environmental threats (Hutchins and Lester, 2006:434). They may also alert governmental institutions to public interest in specific issues, thus pushing them up the political agenda (Cracknell, 1993; Brulle, 1996; Dispensa and Brulle, 2003; Noy, 2009). Since social movements usually neither have widespread, direct ties to the public nor to decision makers, they often rely on media to disseminate their message (Noy, 2009).

A major problem is, of course, what factors may affect the relationship between media and movements, and more specifically, the former's attention to the latter's stances and actions. On this ground, a number of interpretations have been proposed. Some have pointed at the role of frames (Goffman, 1974), namely, interpretive packages that condense and summarize the facts of the world 'out there' in a way that eases our understanding of them (Benford, 1993a,b; Gamson, 1992; Snow et al., 1986; Snow and Benford, 1988). Collective action frames may be intentionally and strategically formulated by social movements - and analogously by their opponents - to garner general public support for their cause and to attract and mobilize potential constituents (Gamson and Modigliani, 1989; Noy, 2009; Scheufele, 1999; Snow et al., 1986; Snow and Benford, 1988). Frames are also simultaneously used by media to simplify presentation of complicated issues in the course of reporting the news (Anderson, 1997; Dispensa and Brulle, 2003; Gamson et al., 1992; Ryan, 1991; Scheufele, 1999; Tuchman, 1978).

Other observers have stressed the asymmetrical dependency between social movements and media, with the former much more dependent on the latter than the other way around (Entman and Rojecki, 1993; Gitlin, 1980; McCarthy et al., 1996; Baylor, 1996; Klandermans and Goslinga, 1996; Gamson and Modigliani, 1989; Carroll and Hackett, 2006). Still others have focused on the peculiarities of news reporting as a profession, emphasizing the tensions between the theoretical ideal of objective coverage emphasized in academic journalism programs and the more 'managed' demands of the real world (Croteau and Hoynes, 2003; Scheufele, 1999; Shoemaker and Reese, 1996; Tuchman, 1978; Ericson, 1991; Gitlin, 1980; see also Carroll and Hackett, 2006). The inherent tendency for the media to promote hegemonic groups and the status-quo has also been considered (Gitlin, 1980; Marchak, 1983; Croteau and Hoynes, 2003); so have the relative weight of professional norms and values, journalistic routines, and ideological or political orientations of journalists (Anderson, 1997; Scheufele, 1999; Tuchman, 1978; Ryan, 1991; Shoemaker and Reese, 1996).

However, for all their richness, the interpretations mentioned above have paid scarce attention to the properties of the 'sources' of information, namely, movement activists. We try to remedy this omission here. We are indeed convinced that taking them into account may generate important insights about what actually gets into the news.

\subsection{Attributes versus relational properties}

Four specific source characteristics are considered in this study. Three of them refer to standard individual attributes, namely: (1) whether or not the source is radical; (2) the source's gender; and (3) whether or not the source holds a formal leadership position in some movement organization. The fourth property is, in contrast, a relational property, as it consists of the source's centrality in the movement's communication network.

\subsection{Radicalism}

Opinions vary as to how radicals get integrated (or fail to get integrated) into the framing discourse and the news. As already mentioned, some believe that media selects content based on the dual objectives of maximizing profit and market share (Croteau and Hoynes, 2003; McAdam et al., 1996), and most typically these objectives are met by covering issues in a contentious, exciting, or sensationalized way. In this way, some propose that since radicals typically present rather extreme views, or commit dramatic actions, they provide ideal content and they are valued by reporters (Killian, 1972; McCarthy et al., 1996; Mueller, 1997; Snyder and Kelly, 1977). This perspective suggests that radicals would commonly be cited using diagnostic frames, because they need to define their own perceptions of the problem - the further 'out there' their perceptions, the better as far as the media is concerned - and also that they would get cited using motivational frames, because of their emotional value. In terms of prognostic frames, however, this perspective implies that citations from radicals should be fairly few in number, simply because the shock value diminishes once reasonable solutions and paths of action are suggested.

Others, however, suggest that radical views and behaviours are too far outside the norm and actually serve to confuse matters (Fitzgerald and Rodgers, 2000; Rootes, 2007; Snow and Benford, 1992). Instead, reporters opt for balance and objectivity, and generally steer away from these types of citations as they only serve to muddy the waters and direct attention away from the real issues. Under this perspective they will opt for more authoritative and accepted sources. Thus, radicals will tend not to get cited as frequently across all types of core framing tasks.

\subsection{Gender}

Carolyn Merchant (1997) estimates that globally, roughly 80 percent of grassroots environmental activists are female. There is a substantial amount of literature that finds women are generally more environmentally concerned than men and more likely to participate in environmental organizations (Blake et al., 1996; Steger and Witt, 1989; Zelezny et al., 2000). However, Merchant (1997) also notes that a distinct minority of these women are actually formal leaders.

Nevertheless, many researchers have found that it is more likely that males will be leaders of social movements than females (see Brinton, 1952; Flacks, 1971; Merchant, 1997; Morris and Staggenborg, 2004; Oberschall, 1973; Paxton et al., 2007). Morris and Staggenborg (2004:180) state that "insofar as men have traditionally occupied positions of authority and dominated mixed-sex interaction, the gendered character of leadership in many movements is not surprising."

Work has also been done on the networking roles that females play in social movements. Robnett (1997:191), in her detailed study 
of the role of African-American in the U.S. civil rights movement, argues that while females generally did not hold formal leadership roles, they did often function as an "intermediate layer of leadership," bridging the formal leaders with the movement constituents. In a similar sense, Wilson (1998:50), when discussing the environmental movement of British Columbia, says:

Although men continue hold a disproportionate share of leadership positions in the movement, women are well represented at the activist level, with women such as Colleen McCrory, Vicky Husband, Tzeporah Berman, Sharon Chow, Rosemary Fox, Valerie Langer, and Adrianne Carr exerting a strong influence on the movements' priorities and strategies, it seems fair to say that women are closer to attaining equality here than they are in political parties or most other interest groups.

\subsection{Formal leadership roles}

Formal social movement organization leaders have certain responsibilities and tackle an array of different tasks: "They inspire commitment, mobilize resources, create and recognize opportunities, devise strategies, frame demands, and influence outcomes" (Morris and Staggenborg, 2004:171). In sum, leaders strive to garner general public support for the movement's cause and promote mobilization of constituents (Snow and Benford, 1988). Morris and Staggenborg (2004:186) clearly argue:

Social movement leaders, as actors most centrally engaged in movement framing, devise media strategy, make judgments regarding information provided to media, conduct press conferences, and are usually sought out by media to serve as movement spokespersons.

\subsection{Social network centrality}

The correspondence between formal leadership roles and substantial influence is, however, far from obvious. According to some observers, "there is an ingrained tendency in social movement organizations to question leadership positions" (Klandermans, 1989:217), and to reject bureaucratic, hierarchical structures in favour of less centralized, more egalitarian organizational forms, in which the relative influence and importance of particular individuals tend to be downplayed in favour of the intentions of the movement as a whole (Morris and Staggenborg, 2004). 'Leaders' are defined in terms of factors such as influence, authority, and status, rather than formal roles (Diani, 1995, 2003; Nepstad and Bob, 2006). This is consistent with insights from social network theory, according to which actors that are more central in their networks possess greater influence, authority, and/or status (Bonacich, 1987; Cook et al., 1983; Faust, 1997; Freeman, 1979; Knoke, 1994; Knoke and Burt, 1983; Marsden, 1983; Wasserman and Faust, 1994). As Freeman (1979:219) states: "With respect to communication, a point [actor] with relatively high degree [centrality] is somehow 'in the thick of things'." (See also Freeman's 1979 discussion of work by Bavelas, 1948; Cohn and Marriott, 1958; Shaw, 1954; Shimbel, 1953).

Actors' centrality in a movement's communication network would then grant them control over the flow and transmission of information. Most central activists not only would have direct links with multiple others inside the movement, affecting intramovement flow, but because of their unique central location might also provide indirect paths through which they affect intermovement information exchange with otherwise unconnected individuals or groups (Diani, 1995, 2003; Friedkin, 1982). Available - if limited - evidence suggests that centrality within a movement network somehow correlates with stronger ties to external actors, including political representatives and - most significantly here - the media: "The most central actors were, in other words, more likely to be perceived by media and external observers as the actors entitled to speak up on behalf of the movement as a whole" (Diani, 2003: 110; contra: Diani, forthcoming, chapter 8$).^{1}$ This is consistent with claims that status plays a significant role in deciding whom a journalist will go to as a source (Benford and Snow, 2000), and that journalists would rather engage with a "responsible spokesman" than with a formal, yet non credible, leader (Tuchman, 1978:112; also see Morris and Staggenborg, 2004).

\subsection{Analytic strategy and hypotheses}

The overall objective of this study is to investigate how radicalism, gender, formal leadership roles, and social network position interact as predictors of media coverage. To this purpose, a series of hypotheses were developed and are tested. First, correlational analyses are utilized to explore particular bivariate relationships. Second, multiple regression analyses are used to explore hypotheses regarding the relationships between three of the independent variables (social network centrality, leadership, gender and radicalism) and the dependent variable. Finally, interviews with print-news media-workers who were key players in covering the British Columbia forestry conflict are used to supplement findings, adding further insight to the interpretation of the results.

The first issue examined is the bivariate relationship between leadership and social network centrality. Though it has not empirically been tested in earlier research, an important question is: Are the formal movement group leaders also the most network-central actors? To explore this issue, the following hypothesis is tested:

H1. Formal leaders will have higher communication-network centrality scores than non-leaders.

Researchers also argue that one of their primary responsibilities of formal leaders is the task of communicating with the public, and this typically occurs via the media (Morris and Staggenborg, 2004; Snow and Benford, 1998). To examine this issue, the following hypothesis is explored:

H2. Formal leadership will be positively associated with media coverage.

The literature suggests that actors who are more central to their movement's communication network will have influence over the flow and dissemination of information (Bavelas, 1948; Cohn and Marriott, 1958; Freeman, 1979; Shaw, 1954; Shimbel, 1953), and this should directly relate to whom journalists approach for information. Thus:

H3. Network centrality will be positively associated with media coverage.

Some scholars suggest that males tend to be leaders of social movement groups (Brinton, 1952; Flacks, 1971; Merchant, 1997; Morris and Staggenborg, 2004; Oberschall, 1973; Paxton et al., 2007). Hence the following bivariate hypothesis is tested:

\section{H4. Males will be more likely to be leaders than females}

Work by Robnett (1997) and others suggests that women may hold more central roles in the movement outside of formal leadership positions, and Wilson (1998) has suggested that women held key positions in the British Columbia environmental movement. Thus:

\footnotetext{
1 Diani is speaking specifically about social movement organizations, there is little reason to believe a similar process does not operate at the level of the individual
} activist. 
H5. Women will have relatively higher centrality scores than males.

Finally, some scholars suggest that the media selects content based its ability to attract market share, and tends to be dramatic and sensationalized (Croteau and Hoynes, 2003; McAdam et al., 1996). In this way, we could expect that radicals would be more covered in the print-news media. Others, however, suggest that radicals tend to be marginalized in the media because of the extremeness of their views (Fitzgerald and Rodgers, 2000; Rootes, 2007; Snow and Benford, 1992). In this way, radicals should be less covered than their more moderate counterparts. In this study, the latter is used as the basis for the hypothesis:

H6. Radicals will be less covered than moderates.

\section{The study}

\subsection{The forestry conflict and the environmental movement in British Columbia}

The debate over wilderness preservation in British Columbia has generally been centered in the western part of the province, primarily on the rural, coastal mainland and adjoining Vancouver Island. This vast area contains some of the largest remaining intact tracts of old growth temperate rainforest in the world, but also contains some of the largest and most productive industrial forests on the globe.

For many, the battle to preserve old growth forests in coastal British Columbia was best symbolized by the summer of 1993 , when local, national, and international news covered the arrests of over 850 protesters throughout the summer who collectively blockaded logging access to forestlands in Clayoquot Sound, Vancouver Island - an event that became known as the single largest act of civil disobedience in Canadian history. However, while this summer of 1993 is familiar to many, the forestry conflict in the province has a much longer history.

In British Columbia, the forest industry has been one of the greatest contributors to the provincial economy for most of the province's history (Barnes and Hayter, 1997; Drushka, 1999; Drushka et al., 1993; Hayter, 2000; Marchak, 1983; Marchak et al., 1999; Markey et al., 2005). ${ }^{2}$ This economic dependency has resulted in a complicated set of relationships between the various stakeholders, including the forest industry, forest workers and rural communities, the government, and the province's citizenry. Historically - and in many instances and areas still today substantial primary and secondary employment was provided by the industry and, thus, support for its well-being has been fairly widespread (Marchak, 1983). Laws and regulations were typically drafted greatly favouring industry access to timber (Drushka, 1999), while providing few enforceable environmental protections.

Decreasing amounts of old growth and the related damages to the environment by widespread and often unchecked logging became widely recognized as critical issues by the provincial citizenry and became an important political issue in the late 1980s and 1990s (Wilson, 1998). As a result, an environmental movement active in fighting for greater restrictions on the forest industry arose. Amongst Canadian provinces, the environmental movement is most prominent in British Columbia. Indeed support for, and participation in the movement is quite substantial. For instance, based on survey research conducted in the 1990s, Blake et al. (1996)

\footnotetext{
2 Note that the province has been home to aboriginal, or First Nation, peoples for many thousands of years. Though they have extensively used forest resources for subsistence throughout history, the forest industry described here did not become relevant until after white settlers arrived from Europe in the late 18th century.
}

estimated that about $13 \%$ of British Columbia residents have membership in at least one environmental organization.

\section{The data}

In this paper we combine evidence from two initially unrelated data sets. The first consists of relational (and some attribute) data for 34 individuals active in the environmental movement in the Vancouver and Victoria, British Columbia regions in the late 1980s and early 1990s. ${ }^{3}$ Their media coverage is measured by drawing upon a database containing records of print-news media citations relating to the forestry conflict in western British Columbia between 1986 and 1992. In addition, qualitative data from faceto-face interviews held with key news-workers operating in the field during the 1980s and 1990s are also used to supplement the findings and discussion.

\subsection{Social network data}

The social network data were collected for prior studies of the underlying structure and functioning of environmental movement groups active in the British Columbia forestry conflict (see Tindall, 1994, 2002; Tindall et al., 2003). In that context, a survey was conducted of 28 activists who were part of the environmental movement. Amongst other questions, they were asked to indicate whether they had ties to a predetermined list of individuals active in the forestry conflict.

Regarding sampling of the respondents for this analysis, an initial study (Tindall, 1994, 2002; Tindall et al., 2003) focused on two adjacent geographic areas on Vancouver Island, British Columbia: the Carmanah Valley, and the Walbran Valley. These areas contain largely untouched old growth rainforests, and were contested by a number of environmental social movement organizations (see Tindall and Begoray, 1993). For an initial set of interviews, a purposive/quota sampling approach was employed to identify several core organization members (leaders, core activists, and staff members) from each of five formal and non-formal organizations (the Carmanah Forestry Society, Friends of Carmanah/Walbran, the Environmental Youth Alliance, the Sierra Club, and the Western Canada Wilderness Committee) that had mobilized around preserving the Carmanah and Walbran Valleys. As the research progressed, a new wave of mobilization developed around trying to protect the Clayoquot Sound area on Vancouver Island, thus the sampling and interviews were expanded to include core organization members from several additional organizations (Friends of Clayoquot Sound, and Greenpeace) that were highly involved in the Clayoquot campaign. We refer to the people who were interviewed as the "respondents". In terms of organizational size for the groups the respondents were sampled from, the formal organizations tended to have larger memberships (hundreds to tens of thousands), while the informal organizations tended to have smaller memberships (in the dozens or fewer).

The questionnaire allowed the 28 respondents (egos) to indicate ties to a wide range of actors (targets) who participated in the forestry debates, including members of environmental groups, individual activists, representatives of business, politicians, union leaders, and First Nation representatives. Since the focus of this paper is on how the media interacted specifically with the social movement organizations in terms of selecting sources, only the relational data for the 34 targets that were members of environmental movement organizations are retained.

\footnotetext{
3 The matrix used for collecting the social network data is presented in Appendix
} 
The targets were identified through several means, including knowledge obtained through field research, prior reviews of media coverage, and membership lists. Twelve of the 34 environmentalists who were listed as "targets" were also "respondents". ${ }^{4}$ There were targets from all of the organizations that the respondents were sampled from (except Greenpeace), and in addition there were two additional organizations represented in the targets (the Sea Shepherd Society, and Sisters for Non-Violent action) as there were prominent British Columbian environmental activists associated with these organizations.

Respondents were asked about several different types of social ties, though only data indicating whether or not the respondent ever communicated with the target is examined in this paper. ${ }^{5}$ The resulting dataset consisted of a two-mode (28 egos $\times 34$ targets), single-relation sociomatrix, where each cell $x_{i j}$ equalled 1 if ego $i$ had a tie to target $j$; otherwise the cell value was 0 .

This communication tie data was used to calculate the social network indegree centrality score for each of the 34 targets. $^{6}$ This score was calculated by summing the total number of survey respondents $i$ who communicated with target $j$. For example, if 23 of the 28 survey respondents indicated that they had communicated with a Target $X$, the indegree centrality score for Target $X$ is 23 . Hence, those targets with a higher indegree score are relatively more central to the British Columbia environmental movement's communication network.

\subsection{Citation data}

As an indicator of media coverage we adopted the number of times that the 34 environmental movement activists ('targets') we just mentioned were cited in the press. The database from which we elicited citations was previously compiled for a study of media coverage of the forestry conflict in British Columbia over the period 1986-1992 (see Cormier and Tindall, 2005). This database contains an array of information on citations from 957 print-news articles collected over the time period that mentioned certain place names, topics, or phrases. ${ }^{7}$ Amongst this information is a tally of the number of 19 particular keyword statements used in each individual article, along with the name of the source that provided it. ${ }^{8}$

The collection of keywords was derived by the original researcher in conjunction with an extensive review of the forestry conflict and personal experience. Newspaper articles, social movement organization publications (posters, flyers, and reports), broadcast-news reports, and discussions with social movement organization members and others active in the conflict were all considered when compiling the keyword list. Subsequently, each of the 19 keywords was later classified as illustrations of one of the core framing tasks identified by Snow and Benford (1988) in

\footnotetext{
${ }^{4}$ Further, we also interviewed several additional targets - but, for varying reasons, we were unable have them complete the network questionnaire.

${ }^{5}$ In addition to the tie types presented in survey but not included in the analyses in this paper were: "I've never heard of this person"; "I've heard of this person but have no contact with him/her"; "I've worked with this person"; "This person is a close friend"; "I like this person", and; "I dislike this person". In this paper we analyze only "communication" networks in order to provide focus, and also because framing is essentially a communicative type of action.

6 The two-mode data were then converted into a bipartite graph of targets by egos, and various centrality measures such as Eigen vector, farness, and closeness were calculated. However, all of these measures were rather similar, and we opted for the simple indegree as we feel it is the easiest to explain and understand.

7 The following places, topics, and phrases were used to select articles "Carmanah," "Walbran," “Clayoquot," "logging and BC" (British Columbia), "forestry and BC," "timber and BC," "environment\$ and BC," "conservation and BC," "park\$ and $\mathrm{BC}$ " ('\$' is a wildcard character).

8 The database also contains information on 30 general 'themes', but because of a much higher degree of inter-coder reliability, only the 19 more specific 'keywords' are used for this study.
}

Table 1

Keyword frame by core framing task.

\begin{tabular}{l}
\hline Diagnostic \\
Biological diversity \\
Clear cutting \\
Ecosystems \\
Marbled Murrelet \\
Spotted Owl \\
Pacific Yew \\
Wilderness \\
Prognostic \\
Civil disobedience \\
Conservation \\
Preservation \\
Selective cutting/harvesting \\
Sustainability \\
Motivational \\
Ancient forests/old growth \\
Giants \\
Gandhi \\
Natural cathedral \\
Sacred \\
Martin Luther king and/or US civil rights movement \\
Brazil of the North
\end{tabular}

their seminal contributions: diagnostic frames, involving not only identifying the problem, but also attribution of cause, blame, or culpability for the situation to someone or some group; prognostic frames, consisting of statements meant to explore and define possible solutions to the problem and strategies meant to resolve them; and motivational frames, consisting of what Benford and Snow (2000:617) quite simply described as a moral "call to arms." Table 1 provides the classification scheme for these keyword frames.

Reference to these framing codes is important because we did not include in our citations dataset any reference to specific environmental activists regardless of its context. Instead, we only counted citations of activists as sources of information on the nature and causes of the forestry conflict (diagnostic role), on its possible solutions (prognostic role), or on the reasons why the public and authorities should act on the forestry issued (motivational role). Although we are not going to explore differences between different types of citations in the present paper, taking them into account will enable us to conduct further explorations of the issue. ${ }^{9}$

Data entry and coding of these articles were done by four coders. Each was given a coding dictionary containing the keywords frames (and themes) and a subsample of articles to evaluate. For all, the entire article was read and the relevant data entered into the database. Intercoder reliability was assessed by selecting 20 articles at random from each coder, and then having the other three coders also enter them. The proportion of times three of the four coders agreed on each keyword frame in each article was calculated. Overall, the mean intercoder reliability was 0.86 and the median was 0.93 .

Two types of sampling were used to collect this citation data with the intent being the best possible representation of national, regional, and local coverage of the issues, as well as ideological orientations (liberal versus conservative). The first sample - representative of the national and regional coverage - was actually a census, and came from searches of Canadian Business and Current Affairs Index using the place names, topics, and phrases mentioned in footnote 7. A broad range of print-news sources were sampled including the Vancouver Sun, the Globe and Mail (National Edition), MacLean's, and Western/B.C. Report. This sample represents the more national and regional coverage of forestry issues. Four

\footnotetext{
${ }^{9}$ We include findings for each of these broad frame types in the tables for descriptive purposes.
} 
Table 2

Descriptive statistics.

\begin{tabular}{|c|c|c|c|c|c|}
\hline Variable & Mean & Std. dev. & Minimum & Maximum & Description \\
\hline Total citations & 6.18 & 8.325 & 0 & 35 & $\begin{array}{l}\text { Total number of citations appearing in print-news } \\
\text { media attributed to a particular activist }\end{array}$ \\
\hline Diagnostic frames & 2.79 & 3.715 & 0 & 16 & $\begin{array}{l}\text { Number of diagnostic keyword frames appearing in } \\
\text { print-news media attributed to particular activist }\end{array}$ \\
\hline Prognostic frames & 1.76 & 2.893 & 0 & 13 & $\begin{array}{l}\text { Number of prognostic keyword frames appearing in } \\
\text { print-news media attributed to particular activist }\end{array}$ \\
\hline Motivational frames & 1.82 & 2.747 & 0 & 13 & $\begin{array}{l}\text { Number of motivational keyword frames appearing in } \\
\text { print-news media attributed to particular activist }\end{array}$ \\
\hline Social network centrality & 13.00 & 5.810 & 3 & 23 & Communication network indegree centrality score \\
\hline Leadership & 0.26 & 0.448 & 0 & 1 & Indicator of formal leadership role $(1=$ yes $)$ \\
\hline Radicalism & 0.32 & 0.475 & 0 & 1 & Indicator of radicalism ( 1 = yes $)$ \\
\hline Gender & 0.68 & 0.475 & 0 & 1 & Indicator of gender ( 1 = male $)$ \\
\hline
\end{tabular}

$n=34$.

hundred and seven (407) articles were located for the time period January 1986 to December 1992.

The second sample, representing the more local coverage, though not strictly probability-based, was collected using the same criteria as the first sample. This sample was also collected prior to the formulation of the keyword frame coding scheme, and, thus, there is little reason to believe any bias exists in terms of the actual frames analyzed in this paper. Sources included Monday Magazine and the Victoria Times Colonist for the period March 1990 to December $1992 .{ }^{10}$ This sample contains 550 articles.

\subsection{Data management and data file creation}

The 957 news articles contained in the citation database account for a total of 22,004 total citations. Most relevant to this study, however, is that 210 of these citations were from environmental social movement organization members that were listed as targets in the social network instrument. Consequently, for each of the 34 targets (now the cases in a new data file), in addition to their social network indegree centrality score, data on the number of times they were cited in the print-news media mentioning each of the 19 different keyword frames (and thus, the number of times they were cited using each of the three core framing tasks) was derived. In addition, for each of the 34 cases three dichotomous variables were created indicating: (1) whether or not the activist held a formal leadership position in the movement ( $1=$ yes); ( 2 ) whether or not the activist was a member of the radical contingent of the movement $(1=$ yes $)$; and ( 3 ) the individuals' gender $(1=$ male). All of this information was compiled in a single SPSS data file used for the analyses in this paper. Table 2 shows the descriptive statistics and brief descriptions for each of the measures.

\subsection{Qualitative news-worker interviews}

Information used to supplement the findings and discussion in this paper is taken from interviews held with key news-workers who were active in covering the British Columbia forestry conflict between 1996 and 2000. The content analysis data set was used to identify a purpose sample of media workers. The sample is comprised of most of the primary beat writers (plus one newspaper editor) who covered the forestry/environment beat for the newspapers included in the sample for the content analysis. In total,

\footnotetext{
${ }^{10}$ It is worth noting that the time periods covered are not identical: the first sample covered the full time period January 1986 to December 1992, while the second represented a truncated period from March 1990 to December 1992. Note, however, that the focus of this study (the unit of analysis) is not the article, but the cited activist. The information of primary interest is the frequency that certain environmental social movement organization members were cited using certain collective action frames. Thus, this divergence between the time frames is not a serious methodological issue.
}

interviews with 10 news-workers, including one editor and nine journalists are evaluated. The interview participants worked for a variety of British Columbia print-news media outlets, including regional and local newspapers, as well as 'alternative' publications (as noted, covering all of the newspapers included in the sample). All of the participants worked extensively either in forestry or environmental news. A semi structured interview schedule was used, consisting of open-ended questions. The questions covered a broad range of topics related to news work: how news-workers established new story ideas, how much freedom they had to choose their own stories, whether they had been pressured by editors because of their coverage of the environmental movement, and so on. The news-workers were also asked about their relationships with different types of news sources (government, forest industry, environmentalists), which tactics were particularly useful for gaining access to the news media, and their perceptions of the quality of media coverage of forestry conflicts.

\section{Results}

Let us start by looking at the Pearson correlation coefficients for all the variables analyzed in this study (Table 3). ${ }^{11}$ The first hypothesis, $\mathrm{H} 1$, in support of a wide array of published work, hypothesizes a positive relationship between leadership and communication network centrality. However, from Table 3 we see that the leadership measure though somewhat sizable $(r=.29)$ is not significantly associated with the centrality score, thus failing to support H1. This finding is noteworthy as it implies that formal leadership and social network centrality may be different phenomena - at least with this movement, leaders are not the most central actors in the environmental movement's communication network.

Likewise, with regard to $\mathrm{H} 2$, we see from Table 3 that the formal leadership indicator is not statistically significantly related to citations. Hence, those who were formal leaders were not cited more than non-leaders. This suggests that formal office not be necessarily a predictor of preferential attention from the press.

From Table 3 we also see support for $\mathrm{H} 3$ when we note that the network centrality score is very significantly, positively associated with citations. Thus, those who were more central to the movement's communication network actually got more attention from the press - a finding that persists when simultaneously modelling all the independent variables in the next section. This relationship between network centrality and media coverage is graphically represented in Fig. 1. Here, the squares represent the nodes for the

\footnotetext{
11 Note that in the tables, for media data we provide results for total citations, diagnostic frames, prognostic frames, and motivational frames. In the text, however, we focus more narrowly on the results for total citations. This is how we operationalize media coverage in this paper. The frame data is provided as additional information.
} 
Table 3

Intercorrelations.

\begin{tabular}{|c|c|c|c|c|c|c|c|}
\hline & Total Citations & Diagnostic & Prognostic & Motivational & $\begin{array}{l}\text { Network } \\
\text { centrality } \\
\text { (indegree) }\end{array}$ & Leader & Radical \\
\hline Total citations & - & & & & & & \\
\hline Diagnostic & $.89^{* * *}$ & - & & & & & \\
\hline Prognostic & $.95^{* * *}$ & $.74^{* * *}$ & - & & & & \\
\hline Motivational & $.87^{* * *}$ & $.57^{* * *}$ & $.84^{* * *}$ & - & & & \\
\hline Network centrality (indegree) & $.65^{* * *}$ & $.58^{* * *}$ & $.59^{* * *}$ & $.59^{* * *}$ & - & & \\
\hline Leader $(1=$ yes $)$ & .29 & .18 & .28 & $.34^{*}$ & .29 & - & \\
\hline Radical ( 1 = yes) & $-.35^{*}$ & -.32 & $-.36^{*}$ & -.24 & -.11 & $.44^{* *}$ & - \\
\hline Gender ( 1 = male $)$ & -.02 & .03 & -.08 & -.03 & .10 & -.16 & $-.46^{* *}$ \\
\hline $\begin{array}{rl}n=34 \\
{ }^{*} p \leq .05 \\
{ }^{* *} & p \leq .01 \\
{ }^{* * *} & p \leq .001\end{array}$ & & & & & & & \\
\hline
\end{tabular}

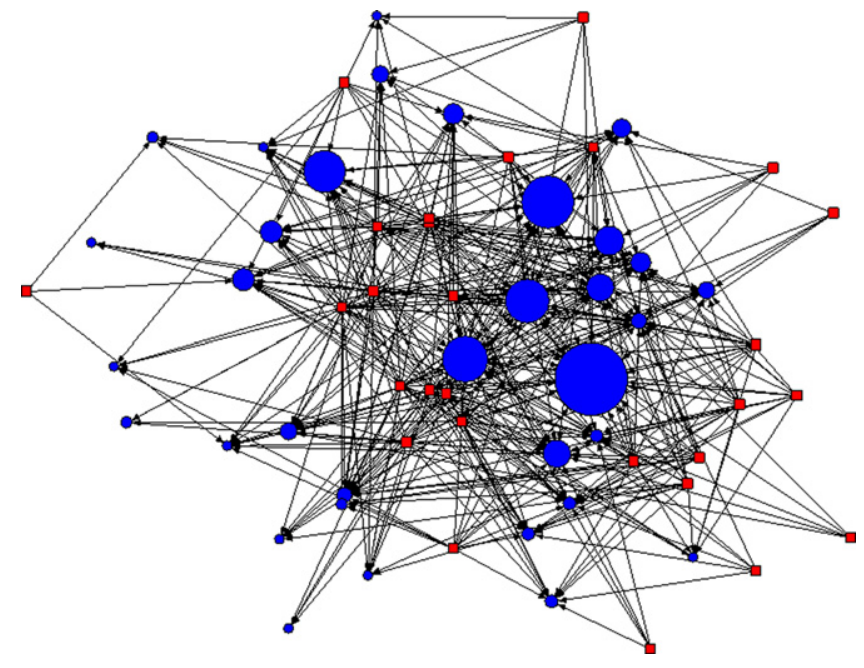

Fig. 1. Two-mode environmentalist communication network, and media coverage.

respondents, while the circles represent the nodes for the targets. The lines represent ties from the respondents to the targets. The size of the circles represents the amount of media coverage (number of citations) that targets received.

These results raise an interesting issue. So far, we found that formal leaders were not the most central actors in the movement's communication network, nor were they significantly associated with rates of citation, while the most central actors were actually cited the most. Is it possible that communication network centrality and formal leadership are different phenomena? To assess this, the first order partial correlation was calculated for total citations and centrality controlling for leadership. If the partial correlation coefficient substantially decreases as compared to the zero order correlation between total citations and centrality, we have evidence to suggest that leadership, at least in part, underlies centrality; if the correlation coefficient does not substantially change, this would support the idea that centrality and leadership are indeed different things. It turns out that the correlation of citations and centrality controlling for leadership is .62, which is not notably different from the zero order correlation of .65. Thus, there is evidence to suggest that leadership and communication network centrality in the BC wilderness preservation movement are indeed different phenomena. ${ }^{12}$

12 It is important to note here that we explore only the communication network for this movement. Thus, while we claim that leadership appears to be different from
The next two hypotheses examine the role of gender. First note that the correlation between gender and formal leadership is not significant, thus failing to support $\mathrm{H} 4$. Hence, the general claim that males are more likely to be social movement organization leaders is not supported by these data. Second, also notice that gender is not associated with social network centrality, thus failing to support H5. Hence, it appears that women did not tend to have more central roles in the environmental movement's communication network. It is also worth noting that, according to Table 3, the relationship between radicalism and gender is significant, but with a negative correlation, suggesting that, all else being equal, women were more likely to be radical than men.

How do the different variables combine in a more complex explanatory model? Table 4 shows the results for an individual quasi-Poisson generalized linear model, ${ }^{13}$ where media coverage (number of total citations) is evaluated as function of network centrality, plus the four actor attributes. ${ }^{14}$ First, note that a higher level of centrality in the environmental movement's communication network is associated with higher rates of citation (supporting H3). Table 4 also shows that moderates are more likely to be cited in the press (supporting H6). Formal leadership is not significant (failing to support H2), showing that leaders are not the individuals who are communicating most often with the media. Also, gender is not significant, suggesting that neither males nor females are a preferred source. $^{15}$

Our results partially support earlier findings, but also depart from conventional wisdom in non negligible ways. On the one hand,

centrality here, this refers specifically to the communication network, which may be different from other types of networks existing within the movement.

13 Note that the models analyzed in this section were not derived specifically for the estimation of coefficient values and these models are not intended to be generalizable. This study is meant to describe an historical phenomenon, not predict future events. The dynamic nature of social events suggests that findings here will apply to this movement at this point in time - too many factors affect the structure and functioning of this movement (as with other movements) and using the results found here to predict outcomes of other movements requires careful thought. We are more interested in the relationship between variables more than the accuracy of the point estimates. Further the relatively small sample size makes any prediction or generalization hazardous.

${ }^{14}$ Generalized linear modelling procedures were used instead of more familiar ordinary least squares (OLS) regressions because the dependent variables are counts. Further, quasi-Poisson distribution functions were chosen because all the dependent variables, in addition to being constrained only to nonnegative values, presented notable over-dispersion (i.e. the standard deviations significantly exceeded the means values - see Table 2 ). This approach results in more conservative and more accurate estimates than OLS procedures (Agresti, 2002).

15 We ran the same regressions on dependent variables consisting of citations associated with diagnostic, prognostic, or motivational framing. We found a consistent pattern of relationships with the independent variables. Only higher levels of social network centrality and non-radicalism proved useful for predicting the rate of citation using these different frame types. 
Table 4

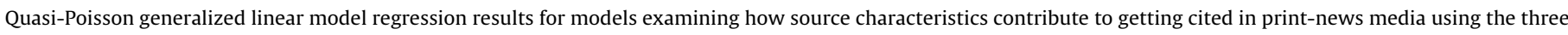
core framing tasks and total citations.

\begin{tabular}{|c|c|c|c|c|}
\hline & Total citations & Diagnostic & Prognostic & Motivational \\
\hline Network centrality (indegree) & $.14(.032)^{* * *}$ & $.13(.042)^{* *}$ & $.15(.036)^{* * *}$ & $.16(.042)^{* * *}$ \\
\hline Formal leader $($ yes $=1)$ & $.51(.303)$ & $.28(.431)$ & $.64(.325)$ & $.70(.385)$ \\
\hline Radical group (yes = 1 ) & $-1.46(.416)^{* *}$ & $-1.22(.559)^{*}$ & $-2.37(.617)^{* * *}$ & $-1.17(.474)^{*}$ \\
\hline Gender $($ male $=1)$ & $-.23(.272)$ & $-.13(.393)$ & $-.42(.284)$ & $-.17(.342)$ \\
\hline Intercept & $-.14(.604)$ & $-.71(.807)$ & $-1.40(.686)$ & $-1.963(.901)^{*}$ \\
\hline
\end{tabular}

Note: $n=34$ for all. Standard errors in parentheses.

${ }^{*} p \leq .05$.

${ }^{* *} p \leq .01$.

$p \leq .001$

the fact that activists who were more central in the movement communication network were also more cited in the press is consistent with studies like Diani's (2003). Admittedly, Diani looked at the correlation between network centrality and the presence of collaborations with local and national media, while we focus on media coverage. Still, both studies found a positive relation between occupying a central position within informal movement networks and stronger contacts with the media, however defined.

On the other hand, the fact that moderates get stronger coverage than radicals might be at least partially at odds with the fact that highly contentious, possibly violent protest events have much better chances of being reported than more moderate ones (Koopmans and Rucht, 2002, 246-251). To add further insight to this finding we now turn to the qualitative interviews conducted with news-workers who were active in reporting on the forestry conflict in British Columbia during this time. While the quantitative results indicate that radicals are not cited most, they did come up in conversations with reporters.

Reporters indicate that covering drama admittedly has some initial appeal, and is often necessary given the scale and scope of certain protest events such as the events surrounding Clayoquot Sound. More important, however, these reporters also state that when covering ongoing conflicts, at some point a shift must be made towards reporting on the underlying issues. Often, this will quickly steer coverage away from more radical groups who typically participate in the drama and reorient coverage towards the more moderate groups who are able to provide more credible and reliable information. This point was repeated throughout the newsworker interviews when they were asked what factors affected their selection of stories and sources:

... after a while certain reporters get to a point in a beat, you're not looking at covering another demonstration. You're looking at sources who can point you to good information (Interview \#4).

...what I was always looking for was the reliability of the information...there are some groups which are quite reliable and there are others who aren't (Interview \#2).

Credibility was the big factor (Interview \#5).

In general, these workers indicated that they tended to filter sources, preferring those that "tended to be less zealous" (Interview \#3) - thus countering the general claim that media automatically favours sensationalization and drama. Instead, they preferred sources who they personally felt were more reliable and credible.

\section{Discussion and conclusion}

We will start out by briefly discussing some of the challenges faced by scholars of social movements and social networks, and by reviewing our somewhat novel approach to two-mode network analysis. Following this discussion, we will turn to substantive and theoretical issues raised by this research.

Arguably the most useful and most frequently used data gathering technique for social network research is the name roster. However, for most social movement research this technique is not practical to use. First, some IRB Ethics Boards will not allow its use because those named on the list have not given prior consent. Second, most social movement organizations will not pass membership lists over to researchers. Third, in western, liberal democracies, most social movement activity is comprised of large formal social movement organizations whose membership lists are too large to use without network sampling.

Another frequently used social network data gathering technique is the name generator. However, name generators tend to not be practical with very large organizations (where members might only know the names of a relatively small number of other members). This type of technique is useful for constructing egonetwork data, but much more difficult under these circumstances for constructing models of whole networks.

A commonly used approach in social networks and social movement research is to examine the extent to which individuals are tied through organizations. This is the classic two-mode approach described by Breiger, 1974; Brieger (1974; see also Diani, 2002). This is useful for a variety of purposes, but it only gives a limited view of how individuals are connected to one another.

In the present study we adopt an approach that overcomes a number of these challenges. Because the target individuals on the network instrument were identified through public sources, this avoids the IRB problem of needing consent to identify these individuals on the network instrument. We then utilized a sample of movement members, and examined their relationships with the target individuals (a subset of whom, were included in the sample). This gave us a measure of the indegree of the target individuals. Thus, through this procedure, we obtained network measures on prominent core activists, and we were able to correlate their structural position (as indicated by centrality) with their prominence (in offering particular social movement frames) in the print news media.

The purpose of this study was to evaluate the role that the structural location of actors, and their attributes, play in determining what gets reported in the print-news media coverage of the British Columbia forestry conflict. An array of hypotheses was tested some supported, some not - and additional insights were garnered from observing unexpected findings.

Noteworthy findings arose with relation to gender. First, the analysis did not show that men were more likely to be formal leaders (failing to support H4) - a notion that previously had significant support in the literature (but that said, at the same time, women were not more likely to be leaders either). Another finding was that women were not more likely to be central players in the environmental movement's communication network (failing to support H5) (but neither were men). Robnett (1997) suggests 
that women often take on key, central roles in social movements as they attend to the day-to-day operations of the movement group, but this was not supported here. For the most part, gender was insignificant throughout these analyses (the only exception being that females were more likely to be members of radical groups). Wilson (1998) suggests that women have played a more significant role in the British Columbia environmental movement than in many other movements, and these results may well point to the significance of women (or at least higher degree of gender equity) in this particular movement.

One of the most surprising results was found in terms of the relationship between social network centrality and formal movement group leadership. More specifically, it was the actual lack of a significant relationship between the two variables that was most interesting (failure to support $\mathrm{H} 1$ ), indicating these are two different phenomena. Some have generalized, proclaiming that the main task of movement leaders is to forward the movement's message (usually in the form of collective action frames) by interacting with media, and further, that the media seeks these leaders out to act as spokespeople (Morris and Staggenborg, 2004). Others, however, have argued that instead of formal leaders, other uniquely placed individuals carry the responsibility of communicating with media (Diani, 1995, 2003). When we note that without exception, social network centrality is significantly related to all three of the core framing tasks (supporting H3), while formal leadership is related to none (failing to support H2), we have clear support for the latter, but not the former.

In terms of network centrality, a wide array of literature cites the fact that individuals who are most central to the movement's communication networks also effectively have control over the flow and transmission of information (see Bavelas, 1948; Cohn and Marriott, 1958; Freeman, 1979; Shaw, 1954; Shimbel, 1953). This should also translate to rates of communication with the media. However, the nature of this relationship is complex and is an avenue ripe for further research. Is it a process internal to a movement that affects who is elevated to positions of status and influence (and thus, network centrality), or is that journalists seek out credible and reliable 'spokespeople', regardless of the activists' structural position? Though it cannot be determined definitively from the data examined in this paper, both internal and external processes are likely at work. On the one hand, internal factors such a charismatic appeal, popularity, level of overall involvement in the movement, and responsibilities likely affect network centrality; on the other hand, journalists do have preferences and have established relationships that they continually turn to for information. Finding legitimate and publishable sources is a time consuming activity, and with often tight deadlines, reporters typically return to the same sources time after time. In this way, the collection of sources a journalist builds throughout their career is one of the most valuable tools they possess in their trade - perhaps a form of social capital.

Significant theorizing has also been done with regards to the role that radicalism plays in media. As mentioned earlier, one commonly held view posits that journalists search out dramatic, confrontational, and exciting material and individuals to report on
(Carroll and Hackett, 2006; Gitlin, 1980). The basic claim is that since economic concerns govern editorial decision making, sensational news is preferred because it tends to maximize readership and, thus, amass the greatest proportion of market share. Successful reporters will be those who are able to present the news in the most dramatic way possible. Consequently, under this view, sensationalized coverage of the radical contingent of a movement should frequently appear in the news. The other popular view portrays the news industry as being essentially governed by the operational values of objectivity and balance. Under this perspective, while certain social and organizational constraints certainly exist, they are mediated by the overarching goal of presenting the news in an unbiased manner. The multiple regression results show that there is little support for the former, by showing that non-radicals are actually cited more.

In summary, this paper shows that only two of the quantitatively evaluated measures are associated with rates of citation: communication network centrality and radicalism. But this is not the whole story. In addition, the news-worker interviews reveal that credibility is a critical characteristic of an environmental movement source. However, some qualifications about the findings need to be offered. The sample size used in the quantitative analysis is somewhat small $(n=34)$, and the sampling technique employed does not allow generalization to a larger population (beyond the case studied here). Never the less, the findings reported here are theoretically and empirically interesting, and on theoretical grounds we might expect to see similar processes in other social movements with similar contexts (such as modern liberal democracies). While we cannot generalize empirically, the processes described here merit further investigation by future researchers.

This work opens the door for a wide range of future work looking at the movement-media relationship. What other attributes of activists affect the rates at which they are cited in the news? Who is more responsible for influencing news content, social movement actors or journalists? Do the results mentioned in this paper carry over to other formats, such as radio or television? These questions and an array of others need to be answered before we can say we really have a hold on the movement-media relationship.

In the present paper we have provided an analysis of the relationship between network centrality (based on a communication network of environmental activists) and media coverage (how frequently the activists are cited endorsing particular frames in the print media). While we have utilized "frames" to operationalize media coverage, we have not provided a theoretical analysis of the relationship of network structure to the differential success of different frames. Our empirical results show that centrality appears to have similar correlations with frame citation for the different types of frames explored here. But the development of a fuller theoretical account of the relationship between network structure and differential framing is an avenue for potential future research.

\section{Appendix A.}

Table A1. 


\section{Table A1}

Social network matrix (names-removed).

\begin{tabular}{|c|c|c|c|c|c|c|c|c|c|}
\hline Names & $\begin{array}{l}\text { I've never } \\
\text { heard of this } \\
\text { person }\end{array}$ & $\begin{array}{l}\text { I've heard of } \\
\text { this person but } \\
\text { have no contact } \\
\text { with him/her }\end{array}$ & $\begin{array}{l}\text { I've talked to } \\
\text { this person at } \\
\text { least once }\end{array}$ & $\begin{array}{l}\text { I talk to this person } \\
\text { at least a few times } \\
\text { a year, but less } \\
\text { than once a month }\end{array}$ & $\begin{array}{l}\text { I talk to this } \\
\text { person at least } \\
\text { once a month }\end{array}$ & $\begin{array}{l}\text { I've worked } \\
\text { with this } \\
\text { person }\end{array}$ & $\begin{array}{l}\text { This person is } \\
\text { a close friend } \\
\text { of mine }\end{array}$ & $\begin{array}{l}\text { I like } \\
\text { this } \\
\text { person }\end{array}$ & $\begin{array}{l}\text { I dislike } \\
\text { this } \\
\text { person }\end{array}$ \\
\hline
\end{tabular}

\section{Person 1}

Person 2

Person 3

Person 4

$\ldots$

\section{References}

Agresti, A., 2002. Categorical Data Analysis, 2nd ed. Wiley-Interscience, Hoboken.

Anderson, A., 1997. Media, Culture, and the Environment. Rutgers University Press, New Brunswick.

Barnes, T.J., Hayter, R., 1997. Troubles in the rainforest: British Columbia's forest economy in transition. Canadian Western Geographical Series \#33, vol. 33. Western Geographical Press, Victoria.

Bavelas, A., 1948. A mathematical model for group structures. Human Organization 7, 16-30.

Baylor, T., 1996. Media framing of movement protest: the case of the American Indian protest. Social Science Journal 33, 241-255.

Benford, R.D., 1993a. Frame disputes within the nuclear disarmament movement. Social Forces 71, 677-701.

Benford, R.D., 1993b. You could be the hundredth monkey: collective action frames and vocabularies of motive within the nuclear disarmament movement. The Sociological Quarterly 34, 195-216.

Benford, R.D., Snow, D., 2000. Framing processes and social movements: an overview. Annual Review of Sociology 26, 611-639.

Blake, D.E., Guppy, N., Urmetzer, P., 1996. Being green in BC: public attitudes towards environmental issues. BC Studies 112, 42-61.

Bonacich, P., 1987. Power and centrality: a family of measures. American Journal of Sociology 92, 1170-1182.

Breiger, R.L., 1974. The duality of persons and groups. Social Forces 53, 181-190.

Brinton, C., 1952. The Anatomy of Revolution. Vintage, New York.

Brulle, R.J., 1996. Environmental discourse and social movement organizations: a historical and rhetorical perspective on the development of U.S. Environmental Organizations. Sociological Inquiry 66, 58-83.

Carroll, W.K., Hackett, R.A., 2006. Democratic media activism through the lens of social movement theory. Media, Culture \& Society 28, 83-104.

Cohn, B.S., Marriott, M., 1958. Networks and centers of integration in Indian civilization. Journal of Social Research 1, 1-9.

Cohn, S.F., Barkan, S.E., Halteman, W.A., 2003. Dimensions of participation in a professional social-movement organization. Sociological Inquiry 73, 311-337.

Cook, K., Emerson, R.M., Gillmore, M.R., Yamagishi, T., 1983. The distribution of power in exchange networks: theory and experimental results. Annual Journal of Sociology 89, 275-305.

Cormier, J., Tindall, D.B., 2005. Wood frames: framing the forests in British Columbia. Sociological Focus 31, 1-24.

Cracknell, J., 1993. Issues, arenas, pressure groups and environmental agendas. In: Hansen, A. (Ed.), The Mass Media and Environmental Issues. Leicester University Press, London.

Croteau, D., Hoynes, W., 2003. Media Society: Industries, Images, and Audiences. Pine Forge Press, Thousand Oaks.

Diani, M., 1995. Green Networks: A Structural Analysis of the Italian Environmental Movement. Edinburgh University Press, Edinburgh.

Diani, M., 2002. Network analysis. In: Klandermans, B., Staggebborg, S. (Eds.), Methods of Social Movement Research. University of Minnesota Press, Minneapolis, Minnesota, pp. 173-200.

Diani, M. 2003. 'Leaders' or brokers? Positions and influence in social movement networks. In: Diani, M., McAdam, D. (Eds.), Social Movements and Social Networks: Relational Approaches to Collective Action. Oxford University Press, Oxford, pp. $105-122$.

Diani, M. The Cement of Civil Society: Civic Networks in Local Setting. Unpublished book manuscript, forthcoming.

Dispensa, J.M., Brulle, R.J., 2003. Media's social construction of environmental issues: focus on global warming - a comparative study. The International Journal of Sociology and Social Policy 23, 74-105.

Drushka, K., 1999. In the Bight: The B.C. Forest Industry Today. Harbour Publishing, Madeira Park.

Drushka, K., Nixon, B., Travers, R., 1993. Touch Wood: BC Forests at the Crossroads. Harbour Publishing, Madeira Park.

Entman, R.M., Rojecki, A., 1993. Freezing out the public: elite and media framing of the US anti-nuclear movement. Political Communication 10,155-173.

Ericson, R.V., 1991. Mass media, crime, law and justice. The British Journal of Criminology 31, 219-249.

Faust, K., 1997. Centrality in affiliation networks. Social Networks 19, 157-191.
Fitzgerald, K.J., Rodgers, D.M., 2000. Radical social movement organizations: a theoretical model. The Sociological Quarterly 41, 573-592.

Flacks, R., 1971. Youth and Social Change. Markham, Chicago.

Freeman, L.C., 1979. Centrality in social networks: conceptual clarification. Social Networks 1, 215-239.

Friedkin, N.E., 1982. Information flow through strong and weak ties in intraorganizational social networks. Social Networks 3, 273-285.

Gamson, W., 1992. Talking Politics. Cambridge University Press, Cambridge.

Gamson, W., Croteau, D., Hoynes, W., Sasson, T., 1992. Media images and the social construction of reality. Annual Review of Sociology 18, 373-393.

Gamson, W., Modigliani, A., 1989. Media discourse and public opinion on nuclear power: a constructionist approach. American Journal of Sociology 95 $1-37$.

Gamson, W., Wolfsfeld, G., 1993. Movements and media as interacting systems. Annals, AAPSS 528, 114-125.

Gitlin, T., 1980. The Whole World is Watching: Mass Media and the Unmaking of the New Left. University of California Press, Berkeley.

Goffman, E., 1974. Frame Analysis: An Essay on the Organization of Experience. Northeastern University Press, Boston.

Hayter, R., 2000. Flexible Crossroads: The Restructuring of British Columbia's Forest Economy. UBC Press, Vancouver.

Hutchins, B., Lester, L., 2006. Environmental protest and tap-dancing with the media in the information age. Media, Culture and Society 28, 433-451.

Killian, L.M., 1972. The significance of extremism in the black revolution. Social Problems 20, 41-48.

Klandermans, B., Goslinga, S., 1996. Media discourse, movement publicity, and the generation of collective action frames: theoretical and empirical exercises in meaning construction. In: McAdam, D., McCarthy, J.D., Zald, M.N. (Eds.), Comparative Perspectives on Social Movement Opportunities, Mobilizing, Structures and Framing. Cambridge University Press, Cambridge, pp. 312-337.

Klandermans, B., 1989. Introduction: leadership in decision making. International Social Movement Research 2, 2154-2224.

Knoke, D., 1994. Networks of elite structure and decision making. In: Wasserman, S., Galaskiewicz, J. (Eds.), Advances in Social Network Analysis. Sage, Thousand Oaks.

Knoke, D., Burt, R., 1983. Prominence. In: Burt, R.S., Minor, M.J. (Eds.), Applied Network Analysis. Sage, Beverly Hills.

Koopmans, R., Rucht, R., 2002. Protest event analysis. In: Klandermans, B., Staggebborg, S. (Eds.), Methods of Social Movement Research. University of Minnesota Press, Minneapolis, Minnesota, pp. 231-259.

Marchak, M.P., 1983. Green Gold: The Forest Industry in British Columbia. UBC Press, Vancouver.

Marchak, P.M., Aycock, S.L., Herbert, D.M., 1999. Falldown: Forest Policy in British Columbia. David Suzuki Foundation/Ecotrust Canada, Vancouver.

Markey, S., Pierce, J.T., Vodden, K., Roseland, M., 2005. Second Growth: Community Economic Development in Rural British Columbia. UBC Press, Vancouver.

Marsden, P.V., 1983. Restricted access in networks and models of power. American Journal of Sociology 88, 686-717.

McAdam, D., McCarthy, J., Zald, M., 1996. Comparative Perspectives on Social Movements: Political Opportunities, Mobilizing Structures, and Cultural Framing. Cambridge University Press, Cambridge.

McCarthy, J.D., Smith, J., Zald, M.N., 1996. Assessing public, media, electoral and government agendas. In: McAdam, D., McCarthy, J.D., Zald, M.N. (Eds.), Comparative Perspectives on Social Movement Opportunities, Mobilizing Structures and Framing. Cambridge University Press, Cambridge, pp. 291-311.

Merchant, C., 1997. Earthcare: Women and the Global Environmental Movement Routledge, New York.

Morris, A.D., Staggenborg, S., 2004. Leadership in social movements. In: Snow, D. Soule, S.A., Kriesi, H. (Eds.), The Blackwell Companion to Sociology. Blackwell Publishing, Malden, pp. 171-196.

Mueller, C.M., 1997. International press coverage of East German protest events: 1989. American Sociological Review 62, 820-832.

Nepstad, S.E., Bob, C., 2006. When do leaders matter? Hypotheses on leadership dynamics in social movements. Mobilization 11, 1-22.

Noy, D., 2009. When framing fails: ideas, influence, and resources in San Francisco's homeless policy field. Social Problems 56, 223-242.

Oberschall, A., 1973. Social Conflict and Social Movements. Prentice-Hall, Inc., Englewood Cliffs 
Oliver, P.E., Meyer, D.J., 2003. Networks, diffusion, and cycles of collective action. In: Diani, M., McAdam, D. (Eds.), Social Movements and Social Networks: Relational Approaches to Collective Action. Oxford University Press, Oxford, pp. 173-203.

Paxton, P., Kunovich, S., Hughes, M.M., 2007. Gender in politics. Annual Review of Sociology 33, 263-284.

Robnett, B., 1997. How Long? How Long? African-American Women in the Struggle for Civil Rights. Oxford University Press, New York.

Rootes, C., 2007. Acting locally: the character, contexts, and significance of local environmental mobilisations. Environmental Politics 16, 722-741.

Ryan, C., 1991. Prime Time Activism: Media Strategies for Grassroots Organizing. South End Press, Boston.

Scheufele, D.A., 1999. Framing as a theory of media effects. Journal of Communication 49, 103-122.

Shaw, M.E., 1954. Group structure and the behavior of individuals in small groups. Journal of Psychology 38, 139-149.

Shimbel, A., 1953. Structural parameters of communication networks. Bulletin of Mathematical Biophysics 15, 501-507.

Shoemaker, P.J., Reese, S.D., 1996. Mediating the Message, 2nd ed. Longman, White Plains.

Snow, D.A., Benford, R.D., 1988. Ideology, frame resonance, and participant mobilization. International Social Movement Research 1, 197-218.

Snow, D.A., Benford, R.D., 1992. Master frames and cycles of protest. In: Morris, A.D. Mueller, C.M. (Eds.), Frontiers in Social Movement Theory. Yale University Press, New Haven.

Snow, D.A., Rochford Jr., E.B., Worden, S.K., Benford, R.D., 1986. Frame alignment processes, micromobilization, and movement participation. American Sociological Review 51, 464-481.

Snow, D., Benford, R.D., 1998. Ideology, frame resonance and participant mobilization. International Social Movement Research 1, 197-218.
Snyder, D., Kelly, W.R., 1977. Conflict intensity, media sensitivity and the validity of newspaper data. American Sociological Review 42, 105-123.

Steger, M.A.E., Witt, S.L., 1989. Gender differences in environmental orientations: a comparison of publics and activists in Canada and the US. Western Political Quarterly 42, 627-649.

Tindall, D., 1994. Collective Action in the Rainforest: A Sociological Analysis of Participation in the Vancouver Island Wilderness Preservation Movement. Unpublished Paper Presented In Poster Session of: Social Sciences and the Environment Conference. Ottawa, Canada.

Tindall, D.B., 2002. Social networks, identification and participation in an environmental movement: low-medium cost activism within the British Columbia wilderness preservation movement. Canadian Review of Sociology and Anthropology 39, 413-452.

Tindall, D.B., Begoray, N., 1993. Old Growth Defenders: The Battle for the Carmanah Valley. In: Lerner, S. (Ed.), Environmental Stewardship: Studies in Active Earthkeeping. University of Waterloo Geography Series, Waterloo, Ontario, pp. 269-322.

Tindall, D.B., Davies, S., Mauboulès, C., 2003. Activism and conservation behavior in an environmental movement: the contradictory effects of gender. Society and Natural Resources 16 (10), 909-932.

Tuchman, G., 1978. Making News. Free Press, New York.

Wasserman, S., Faust, K., 1994. Social Network Analysis: Methods and Applications. Cambridge University Press, Cambridge.

Wilson, J., 1998. Talk and Log: Wilderness Politics in British Columbia. UBC Press, Vancouver.

Zelezny, L.C., Chua, P.-P., Aldrich, C., 2000. Elaborating on gender differences in environmentalism. Journal of Social Issues 56, 443-457. 